\title{
Assay of serum immunoreactive trypsin in dried blood spots and the early detection of cystic fibrosis
}

\author{
HC RYLEY,* PG ROBINSON, $\uparrow$ Y YAMASHIRO, $†$ DM BRADLEY $\ddagger$
}

From the Departments of ${ }^{*}$ Medical Microbiology, $†$ Child Health, and $\ddagger$ Medicine, Welsh National School of Medicine, University Hospital of Wales, Heath Park, Cardiff CF4 4 XN

SUMMARY Immunoreactive trypsin (IRT) content in blood spots from 17 cystic fibrosis (CF) children born between 1975-80 were assayed with reagents from two commercial radioimmunoassay kits. The manufacturers' procedures were modified to allow assay of blood spot IRT. Half of the CF samples had a significantly raised IRT content compared to normal blood spots. Of the blood spots from five children whose meconium screening gave negative results, three or five (depending on the kit used) had a raised IRT content. On the other hand, less than $50 \%$ of children initially detected by meconium screening had raised blood spot IRT values. In our hands, analysis of blood spots for IRT does not consistently identify the newborn with CF and offers no advantage over other screening methods.

Methods for cystic fibrosis (CF) screening of neonates that depend on an assessment of pancreatic function miss between $20-30 \%$ of children with the disease $^{1-3}$ and consequently are not considered reliable enough for mass routine screening. ${ }^{4}$ Recently a report by Crossley, Elliott, and Smith ${ }^{5}$ proposed the measurement of serum trypsin as an indicator for the presence of CF in the newborn. Apart from a proposed increase in reliability, this assay could be carried out on the same blood spot specimens that were collected for phenylketonuria (PKU) screening. In a further report, Elliott and Crossley ${ }^{6}$ stated that blood spots collected from 18 CF children born between 1974-9 had raised trypsin contents, three of the 18 had given negative faecal screening results.

Serum trypsin measured by radioimmunoassay appears to be mainly cathodal moving trypsinogen with some trypsin- $\alpha_{1}$ trypsin inhibitor complex ${ }^{7}$ and, depending on the specificity of the antiserum used, anodal moving trypsinogen ${ }^{8}$ Trysin- $\alpha_{2}$ macroglobulin complex, if present, will not be measured in serum $^{7}$ although it may be detected after denaturation in a dried blood spot. Consequently, because of its complex nature, serum trypsin is usually termed immunoreactive trypsin (IRT).

At present, there are two commercial radioimmunoassay kits available for its measurement, both using the principle of "competitive protein

Accepted for publication 23 December 1980 binding," although the final separation of bound and free ligand differs. The kit marketed by Hoechst Pharmaceuticals depends on a double antibody precipitation step whereas the kit marketed by CIS Ltd uses polyethylene glycol precipitation.

Our study developed from the opportunity to evaluate these two methods afforded by the donation of the kits from the manufacturers. As CF screening has been carried out in Cardiff for a number of years, we have been able to compare IRT concentrations in the blood spots from 17 children with $\mathrm{CF}$ born between 1975-80 with the meconium screening results obtained at the time of their birth.

\section{Material and methods}

RADIOIMMUNOASSAY KITS

The radioimmunoassay kits were donated by CIS Ltd, Rex House, North Finchley, London, and Hoechst Pharmaceuticals, Hounslow, Middx and were supplied between January-July 1980.

SERUM IRT

All determinations of serum IRT were carried out using the protocol supplied with the kits.

BLOOD SPOTS

Dried blood spots originally collected for PKU screening but surplus to requirements were used in this investigation. Ten blood spot cards surrounding 
each card from a child with CF were analysed at the same time to provide normal control values with which to compare the CF blood spot content. Each CF card was mixed in with the 10 control cards and all cards were number-coded; the code only being broken after the assays had been completed. Blood spots were examined from a total of 17 infants with CF born between 1975-80 together with the appropriate controls. The examination was carried out with reagents from a single batch of kits bulked together in both cases. Diagnosis of CF in each of the 17 children was made on the basis of a positive sweat test and subsequent clinical status. For the study into the effect of age on IRT content in blood spots, 10 cards per six-month interval between May 1975 and November 1979 were analysed.

\section{ASSAY FOR IRT IN BLOOD SPOTS}

The test kits were not sensitive enough to measure blood spot IRT by using the manufacturers protocol and so the methods were modified as follows. Unless otherwise stated all procedures were carried out at room temperature.

\section{CIS reagents}

Two $4 \mathrm{~mm}$ blood spots were placed in a tube $(12.5 \times 75 \mathrm{~mm})$ and extracted overnight on a rotary shaker into $100 \mu \mathrm{l}$ PBS (phosphate-buffered saline: $8 \mathrm{mMNa} 2 \mathrm{HPO}_{4}, 1.2 \mathrm{mMKH}_{2} \mathrm{PO}_{4}$ with $140 \mathrm{mM} \mathrm{NaCl}$ ) containing $1 \%$ TritonX100. The discs were not removed. Antibody $(40 \mu \mathrm{l})$ was added, followed $1 \mathrm{~h}$ later by $40 \mu \mathrm{l}$ of tracer solution and the mixture left overnight. Rabbit serum $(100 \mu \mathrm{l})$ was then added to each tube followed by $1 \mathrm{ml} 22 \%$ polyethylene glycol (PEG) solution, pH 9.0 (as supplied by CIS) and the tubes stood for $15 \mathrm{~min}$ in an ice bath. The tubes were centrifuged at $2500 \mathrm{~g}$ at $4^{\circ} \mathrm{C}$ for $10 \mathrm{~min}$, the supernatant decanted and the washing with PEG, centrifugation and decanting repeated. Counting was carried out in Packard Autogamma Counter, Model 5110.

The addition of rabbit serum was to ensure complete precipitation of the antigen-antibody complex by a coprecipitation effect. Rabbit serum IRT did not cross-react with the antiserum to human trypsin used in this kit. All samples and standards were analysed in duplicate.

\section{Hoechst reagents}

Four $4 \mathrm{~mm}$ discs were extracted overnight into $200 \mu \mathrm{l}$ PBS containing $1 \%$ TritonX100. The discs were not removed.The following day $50 \mu$ l of antibody was added and the mixture incubated at $37^{\circ} \mathrm{C}$ for $12 \mathrm{~h}$. Tracer $(50 \mu \mathrm{l})$ was then added to each tube, the solutions left for $12 \mathrm{~h}$ at room temperature and $25 \mu \mathrm{l}$ of the second (precipitating) antibody added. After a further $4 \mathrm{~h}, 1 \mathrm{ml}$ of the Hoechst washing solution (PBS) was added, the tubes centrifuged at $2500 \mathrm{~g}$ for $30 \mathrm{~min}$ at $4^{\circ} \mathrm{C}$, the supernatants carefully decanted and the tubes drained on to paper towels.

Although duplicates were used for all standards and the preliminary work, there was insufficient material to carry out more than one assay for each of the retrospective samples.

In both cases, standards were prepared by mixing one volume of manufacturers standard solutions with one volume of packed washed red blood cells. $40 \mu \mathrm{l}$ spots were prepared from these mixtures on PKU test cards and allowed to dry for at least one week before use.

\section{Results}

\section{PRELIMINARY INVESTIGATIONS}

In order to ascertain the validity of the methods used, a number of blood specimens were obtained from adult volunteers. Part of each specimen was used to prepare blood spot test cards and part for serum preparation. The results of the investigation carried out on these specimens are summarised in Table 1.

With the CIS reagents there is a good correlation between blood spot and serum IRT with the means and ranges for each group not significantly different. With the Hoechst reagents, however, the blood spot IRT was consistently higher (about $79 \%$ ) than the corresponding serum value although the correlation between the two values was satisfactory $(0 \cdot 78)$. No correction for variation of haematocrit values

Table 1 Comparison of blood spot and serum IRT

\begin{tabular}{|c|c|c|c|c|}
\hline & \multicolumn{2}{|c|}{ Hoechst reagents } & \multicolumn{2}{|c|}{ CIS reagents } \\
\hline & Blood spot & Serum & Blood spot & Serum \\
\hline $\begin{array}{l}\text { Number of specimens } \\
\text { Mean } \pm \mathrm{SD}(\mathrm{ng} / \mathrm{ml}) \\
\text { Range (ng/ml) } \\
\text { Regression coefficient blood spot } v \text { serum }\end{array}$ & $\begin{array}{l}20 \\
341 \pm 77 \\
187-495\end{array}$ & $\begin{array}{c}20 \\
201 \pm 55 \\
91-311 \\
0 \cdot 78\end{array}$ & $\begin{array}{l}16 \\
20 \cdot 1 \\
12-30\end{array} \pm 5 \cdot 5$ & $\begin{array}{l}16 \\
23 \cdot 6 \pm 6.6 \\
11-34 \\
0.72\end{array}$ \\
\hline $\begin{array}{l}\text { Within batch precision } \\
\text { low IRT } \\
\text { high IRT }\end{array}$ & \multicolumn{2}{|c|}{$\begin{array}{r}11.6 \%(n=13) \\
9 \cdot 5 \%(n=13)\end{array}$} & \multicolumn{2}{|c|}{$\begin{array}{l}19 \cdot 3 \%(n=13) \\
14.9 \%(n=8)\end{array}$} \\
\hline
\end{tabular}


was made when comparing blood spot IRT content with serum IRT. The IRT values with the Hoechst reagents are approximately ten times those for the CIS reagents. This is a reflection of the different standards supplied by the manufacturers (75-1200 $\mathrm{ng} / \mathrm{ml}$ for Hoechst, $2 \cdot 5-200 \mathrm{ng} / \mathrm{ml}$ for CIS) and will only be overcome when an international trypsin standard is available for use in calibrating the reagents.

A regression coefficient of 0.59 was obtained after comparison of IRT content in blood spots estimated by the modified Hoechst assay and the modified CIS assay. A coefficient of 0.52 was obtained when comparing the IRT content in serum as estimated using the original kit protocols.

One blood sample which was not included in the

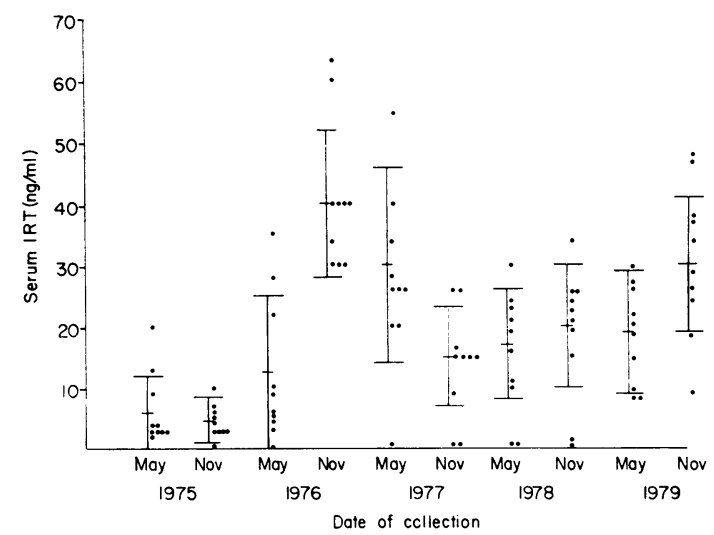

Distribution of serum IRT as measured with the CIS kit in groups of 10 blood spots collected at six-month intervals from May 1975 to November 1979. The mean \pm $S D$ of each group is as illustrated. values for Table 1 gave consistently high IRT concentrations for all blood spot and serum tests with a value greater than two standard deviations above the normal control mean with either test. Follow-up on this volunteer confirmed mild pancreatitis.

\section{MECONIUM SCREENING}

Meconium screening consisted of the determination of the albumin and the albumin: $\alpha_{1}$ trypsin inhibitor ratio. ${ }^{3}$ A positive result was defined as an albumin content greater than $50 \mathrm{mg} / \mathrm{g}$ dry wt and the ratio value higher than $2 \cdot 0$.

\section{EFFECT OF AGE ON IRT CONTENT IN BLOOD SPOTS}

It was necessary to determine to what extent the age of a blood spot influenced its IRT content. Groups of 10 sheets collected at intervals of six months from May 1975 to November 1979 were assayed for IRT with the CIS reagents (Figure). There was a drop in IRT content between May 1979 to November 1977. It then rose back to normal before decreasing again after May 1976. After an initial large drop, the IRT content in each group as estimated with the Hoechst reagents was similar back to May 1975 . From these results it appeared feasible to measure IRT contents in blood spots dating back to 1975 .

SERUM IRT CONTENT OF CF BLOOD SPOTS: COMPARISON WITH MECONIUM SCREENING The CF blood spot was considered to give a positive result if its IRT content was two standard deviations higher than the appropriate control group mean value. On this criterion, nine of the 17 specimens when assayed with the CIS reagents had a positive

Table 2 IRT content of blood spots from CF children

\begin{tabular}{|c|c|c|c|c|c|c|c|c|}
\hline \multirow[t]{2}{*}{ Patients } & \multirow[t]{2}{*}{ Date of birth } & \multicolumn{3}{|c|}{ Measured by modified CIS assay } & \multicolumn{4}{|c|}{ Measured by modified Hoechst assay } \\
\hline & & $\begin{array}{l}C F I R T \\
(n g / m l)\end{array}$ & $\begin{array}{l}\text { Controls }(10) \\
(n g / m l \pm S D)\end{array}$ & Result & $\begin{array}{l}C F I R T \\
(n g / m l)\end{array}$ & $\begin{array}{l}\text { Controls }(10) \\
(n g / m l \quad:-S D)\end{array}$ & Result & Meconium screening \\
\hline A & Apr 75 & 110 & $17 \cdot 7 \div 16 \cdot 6$ & + & 320 & $71 \div 64$ & $\therefore$ & - \\
\hline B & Jul 75 & 90 & $13 \cdot 7 \pm 8.9$ & + & 550 & $120 \pm 79$ & + & + \\
\hline $\mathrm{C}$ & Feb 76 & 15 & $31 \cdot 9 \div 30 \cdot 7$ & - & 55 & $94 \pm 56$ & - & + \\
\hline D & Mar 76 & 42 & $30 \cdot 4 \div 10 \cdot 9$ & - & 55 & $109+69$ & - & + \\
\hline $\mathrm{E}$ & Apr 76 & 64 & $19.9=8.9$ & + & 430 & $111 \pm 58$ & + & - \\
\hline $\mathbf{F}$ & Apr 76 & 68 & $28 \cdot 3 \div 15 \cdot 2$ & + & $<40$ & $91 \pm 57$ & - & + \\
\hline G & Oct 76 & 6 & $14.5 \div 9 \cdot 2$ & - & 55 & $77 \div 54$ & - & $\therefore$ \\
\hline $\mathrm{H}$ & Mar 77 & 65 & $13 \cdot 8 \div 10 \cdot 0$ & $\div$ & 810 & $79 \div 102$ & $\cdots$ & - \\
\hline I & Aug 77 & 55 & $16 \cdot 2+14.0$ & + & 240 & $156 \pm 82$ & - & $\div$ \\
\hline J & May 78 & 31 & $5 \cdot 0+4 \cdot 2$ & $\perp$ & 105 & $85 \pm 64$ & - & t \\
\hline K & June 78 & 38 & $8.6 \quad 5.9$ & $\div$ & 620 & $109 \div 61$ & $\therefore$ & + \\
\hline L & Aug 78 & 24 & $10 \cdot 2 \ldots 16 \cdot 0$ & - & 320 & $123 \div 47$ & - & - \\
\hline $\mathbf{M}$ & Aug 78 & 22 & $20 \cdot 4-10.5$ & - & $<40$ & $118 \pm 82$ & - & + \\
\hline$N$ & Nov 78 & 12 & $14 \cdot 0 \pm 9 \cdot 2$ & - & 50 & $106 \div 72$ & - & + \\
\hline $\mathrm{O}$ & Feb 79 & 250 & $14.0=9 \cdot 2$ & 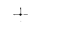 & 700 & $107 \pm 54$ & t. & + \\
\hline $\mathbf{P}$ & Sep 79 & 41 & $38.8 \pm 14.8$ & - & 230 & $107 \pm 54$ & + & - \\
\hline Q & Jan 80 & 14 & $20 \cdot 1+12 \cdot 1$ & - & 180 & $307 \pm 125$ & - & + \\
\hline
\end{tabular}


Table 3 Blood spot serum IRT results compared with meconium screening

\begin{tabular}{|c|c|c|c|c|c|}
\hline & \multirow[t]{2}{*}{ No } & \multicolumn{2}{|c|}{ IRT result (CIS) } & \multicolumn{2}{|c|}{$I R T$ result (Hoechst) } \\
\hline & & Positive & Negative & Positive & Negative \\
\hline $\begin{array}{l}\text { CF infants with } \\
\text { positive meconium } \\
\text { screening results } \\
\text { CF infants with } \\
\text { negative meconium } \\
\text { screening results }\end{array}$ & 12 & 6 & 6 & 3 & 9 \\
\hline
\end{tabular}

IRT content and eight specimens assayed with the Hoechst reagents gave a positive result (Table 2). In all cases when the specimen had a positive IRT content, the ratio of IRT to mean control group IRT was greater than $2 \cdot 0$. Only one negative specimen (specimen $\mathrm{L}$ assayed by the CIS kit) had a ratio higher than $2 \cdot 0$. In the majority of cases the negative specimens had ratios less than 1.0 .

There was some discrepancy between IRT values as assayed by the two kits. Three specimens that gave a positive result with the modified CIS method, had negative results when assayed by the modified Hoechst method and two specimens giving a positive result with the modified Hoechst method had negative results with the modified CIS method. Six of the 17 specimens gave a negative result with both methods. The correlation coefficient for IRT content assayed in the CF blood spots by the two methods was 0.59 and the correlation coefficient for all blood spots assayed was $\mathbf{0} \cdot \mathbf{4 8}$. The serum from patient $Q$ was also assayed 7 days after birth. The values obtained were $19 \mathrm{ng} / \mathrm{ml}$ with the CIS kit and $130 \mathrm{ng} / \mathrm{ml}$ with the Hoechst kit. Both values are within the normal range and confirm the blood spot results (Table 2).

When compared with meconium screening data, only $50 \%$ or less of blood spots from infants with a positive meconium screening result also had a raised IRT content, with whichever kit was used (Table 3). The results on blood spots from children whose meconium screening was negative were better with the modified Hoechst kit assay giving a positive result for all five specimens.

\section{Discussion}

Only limited material was available for this study and if two $12 \mathrm{~mm}$ blood spots had been used per assay as described by Crossley et al., ${ }^{5}$ there would have been insufficient material to evaluate both kits. The methodologies used in this study were developed by changing the parameters for sensitivity in radioimmunoassay as described by Chard. ${ }^{9}$ Preliminary experiments indicated that there was a satisfactory correlation between IRT results estimated in fresh blood spots by the modified tests and IRT results estimated in serum using the manufacturers original protocol, taking into account that the blood spot IRT values were not corrected for varying haematocrit values of the original blood specimens.

Apart from changing the amount of blood spot to be extracted and the assay conditions, it was found that PBS containing $1 \%$ TritonX100 was a more effective extracting solvent than PBS on its own or PBS containing albumin or rabbit serum. Removal of blood spot paper before analysis of extract was found to be unnecessary and may even lead to error. Jt was also important to use kits that were less than four weeks old to obtain full sensitivity of the assay.

Our findings indicated that IRT assay in blood spots was not a reliable test for CF in the newborn which is contrary to the recent report of a retrospective study by Elliott and Crossley. ${ }^{6}$ We have not compared their method with ours on CF blood spots because of limited sample material available but by comparing the test sample against a larger control group, we feel a more accurate assessment can be made than Elliott's group who only compared two controls with their test.

Some caution is needed in correlating falsenegative results obtained in a retrospective study such as this with the results that would have been obtained with the fresh blood spot or serum specimen. We have had to assume that the proportion of IRT eluted from the test and related control samples was similar and also that the amount of decay of IRT was similar. Without preparing specimens with known IRT contents and waiting the appropriate time (1-5 years), these assumptions cannot be tested. The relatively large standard deviation values of the mean IRT content in older blood spots compared with that of fresh spots suggest that the basis of the assumption is questionable.

An additional factor perhaps peculiar to the blood spots collected in the South Wales region was the nature of the filter paper. From a collaborative study on the assessment of methods for IRT estimations in blood spots between our laboratory and others, it is clear that considerably less IRT was eluted from filter paper used in PKU screening in South Wales than from paper used elsewhere (report in preparation). The nature of our filter paper may explain why instead of an expected steady decline of IRT content against time, ${ }^{5}$ the decline was followed by a rise of IRT content in blood spots that were three or more years old. The elution characteristic of the paper may change with age masking the gradual decay of IRT.

There was a poor correlation of the IRT content in blood spots between the result obtained with the Hoechst kit reagents and the CIS kit reagents which at first sight might indicate errors of estimation. However, a similarly poor correlation was obtained with fresh blood spots and with serum whose IRT 
was estimated according to the manufacturers' original protocol. At the moment it is not clear why this discrepancy occurred.

Thus the nature of the filter paper, age of spots, and variation of elution of IRT with the same batch, may all contribute to an increase in the falsenegative score. On the other hand, if the falsenegative results were due solely to the above factors, one might expect an increase in the proportion of negative results with age and more consistent results with spots at various ages. Such trends were not obtained. That one can obtain true falsenegative results with IRT testing was confirmed with the specimens from infant $\mathbf{Q}$. Both the blood spot and serum IRT contents were normal. This infant had meconium ileus and the specimens were taken seven days after birth. The child had sweat sodium and chlorideconcentrations of over $100 \mathrm{mEq}(\mathrm{mmol}) / 1$ when tested at the age of eight weeks and meconium screening was also positive.

In conclusion we feel that although the falsenegative rate may not always be as high as the $50 \%$ found in our study if fresh blood spots are analysed, false-negative results will be obtained. Consequently, taking into account the high cost of the test, we are unable to recommend IRT measurement for CF screening. The positive results obtained with the modified Hoechst method for all five specimens from children whose meconium had given a false-negative result might indicate a limited application for IRT testing. Three of the five specimens were from children known to be at risk but when such children are old enough, a sweat test is considerably cheaper and probably more reliable.

We would like to thank both CIS (UK) Ltd and
Hoechst (UK) Ltd for the free serum IRT radioimmunoassay kits. This work was in part supported by a grant from the Medical Research Council.

\section{References}

1 Prosser R, Owen H, Bull F, et al. Screening for cystic fibrosis by examination of meconium. Arch Dis Child 1974;49:597-601.

${ }^{2}$ Kraemer R, Meier HP, Hammerschlag P, Kaiser D, Sidiropoulos D. Neugeborenen-Screening in der Zystischen Fibrose. Schweiz Med Wochenschr 1977;107 1105-9.

${ }^{3}$ Ryley HC, Neale LM, Brogan TD, Bray PT. Screening for cystic fibrosis in the newborn by meconium analysis. Arch Dis Child 1979;54:92-7.

${ }^{4}$ Committee for a study for evaluation of testing for cystic fibrosis. Report. J Pediatr 1976;88:711-50.

${ }^{5}$ Crossley JR, Elliott RB, Smith PA. Dried blood spot screening for cystic fibrosis in the newborn. Lancet $1979 ; \mathrm{i}: 472-4$.

${ }^{6}$ Elliott RB, Crossley JR. Neonatal dried blood spot screening for cystic fibrosis. In: Sturgess JM. Perspectives in cystic fibrosis. Canadian Cystic Fibrosis Foundation, Canada, 1980:292-6.

${ }^{7}$ Geokas MC, Largman C, Brodrick JW, Johnson JH. Determination of human pancreatic cationic trypsinogen in serum by radioimmunoassay. Am J Physiol 1979;236: E77-E83.

${ }^{8}$ Largman C, Brodrick JW, Geokas MC, Johnson JH. Demonstration of human pancreatic anionic trypsinogen in normal serum by radioimmunoassay. Biochim Biophys Acta 1978;543:450-4.

- Chard T. An introduction to radioimmunoassay and related techniques. Amsterdam, New York, Oxford: NorthHolland, 1978:446-62.

Requests for reprints to: Dr HC Ryley, Department of Medical Microbiology, Welsh National School of Medicine, Heath Park, Cardiff CF4 4XN, Wales. 